\title{
Dissolution Method for Milnacipran Hydrochloride Capsules: Development, Validation, and Study of Changes in Dissolution Rate after Storage
}

\author{
Carolina Lupi Dias*, Rochele Cassanta Rossi, Lisiane Bajerski, and Pedro Eduardo Fröehlich \\ Programa de Pós-Graduação em Ciências Farmacêuticas, Faculdade de Farmácia, Universidade Federal do Rio Grande do Sul (UFRGS). \\ Av. Ipiranga, 2752/704, Porto Alegre - RS CEP 90610-000, Brasil
}

\begin{abstract}
A dissolution test for milnacipran hydrochloride capsules was developed and validated according to international guidelines. After selection of the best conditions, the method was validated using USP Apparatus 1 (baskets), 50-rpm rotation speed, $900 \mathrm{~mL}$ of $0.01 \mathrm{~N} \mathrm{HCl}$, and test time of $60 \mathrm{~min}$. The drug released was determined by both LC-UV (PDA) and UV-D² methods. The kinetic parameters of drug release (mathematical models, $t_{80 \%}$, and dissolution efficiency) were investigated, and the stability of the dosage form was evaluated by analyzing changes in the dissolution rate of milnacipran hydrochloride capsules during storage at $40{ }^{\circ} \mathrm{C}$ and $75 \% \mathrm{RH}$ for different periods.
\end{abstract}

\section{INTRODUCTION}

$\longrightarrow$ issolution testing can provide information not only on the rate and extent of drug absorption in the body but also on the effects of drug biopharmaceutical properties and formulation principles on the release properties of a pharmaceutical product (1). Therefore, in vitro dissolution tests are usually used to assess the lot-to-lot quality of a drug product, guide development of new formulations, an d ensure continued product quality and performance after certain changes such as formulation, manufacturing process, site of manufacture, and the scale-up of the manufacturing process (2). The dissolution procedure requires an apparatus, a dissolution medium, and test conditions that provide a method that is discriminating yet sufficiently rugged and reproducible for day-to-day operation and capable of being transferred between laboratories. With regard to stability, the dissolution test should appropriately reflect relevant changes in the drug product caused by temperature, humidity, photosensitivity, and other stresses over time (3).

Milnacipran hydrochloride (MNC), [101152-94-7], $\mathrm{C}_{15} \mathrm{H}_{22} \mathrm{~N}_{2} \mathrm{O} \cdot \mathrm{HCl}$, molecular weight $282.81 \mathrm{~g} / \mathrm{mol}$ (Figure 1), is a racemic mixture with the chemical name ( \pm )-[1R(S),2S(R)]-2-(aminomethyl)-N,N-diethyl-1-phenylcyclopropanecarboxamide hydrochloride, and its solubility in water is $19 \mathrm{mg} / \mathrm{mL}$ (4-6). MNC is a selective serotonin and norepinephrine reuptake inhibitor (SNRI) indicated as an antidepressant and for the management of fibromyalgia. It shows preferential blockade of norepinephrine reuptake over serotonin and minimal activity at other receptors or transporters (6-8). MNC is well absorbed after

${ }^{*}$ Corresponding author. oral administration with maximum concentrations reached within 2-4 h, and its absorption is not affected by food. It presents an absolute bioavailability of approximately $85-90 \%$ (9). The solubility and absolute bioavailability data for this drug classify it as Class I (high solubility and high permeability) based on the Biopharmaceutical Classification System. This is the case where the drug is well absorbed, and for immediate-release dosage forms that dissolve very rapidly, the absorption rate is controlled by the gastric emptying rate, and some correlation with dissolution rate is expected only if the dissolution is slower than gastric emptying (10).

Methods for quantitation of milnacipran in combination with other antidepressants and their metabolites in biological fluids have been proposed (11-17). However, there is no compendial method to assay milnacipran hydrochloride in pharmaceutical dosage forms. A stability-indicating liquid chromatographic method with UV detection (LC-UV) and a second-order derivative UV spectroscopic method $\left(U V-D^{2}\right)$ for quality control of milnacipran in capsules were developed and validated by the authors (18) according to guidelines (19-21). Therefore, the purpose of this work was to develop and validate a dissolution test for MNC in capsules (50 mg) based on its physicochemical characteristics and apply the LC-UV and UV-D² methods to quantify the drug released from the capsules during the dissolution procedure. The kinetic parameters of drug release were investigated, and the stability of the dosage form was evaluated by analyzing changes in the dissolution rate of MNC capsules over time and in various storage conditions.

\section{EXPERIMENTAL \\ Chemicals}

Milnacipran hydrochloride was purchased from Synfine Research (Canada). The pharmaceutical dosage form 


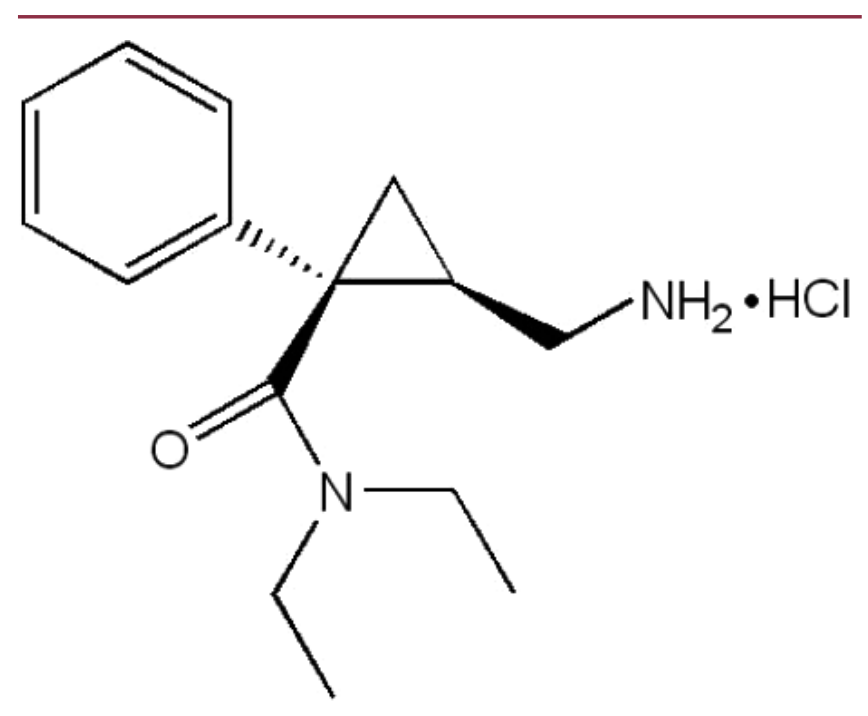

Figure 1. Structure of milnacipran hydrochloride.

(50 $\mathrm{mg}$ ) containing the inactive ingredients dibasic calcium phosphate, povidone, carboxymethylcellulose calcium, colloidal silicon dioxide, magnesium stearate, and talc was commercially available (Pierre Fabre Médicament, Boulogne, França). All chemicals used were of analytical grade, and all solvents were of $L C$ grade. Ultrapure water was from a Millipore system (Milli-Q Plus, Milford, MA, USA).

\section{Apparatus}

The development and validation of the dissolution test was performed using a VANKEL VK 8000 dissolution autosampling station consisting of a bidirectional peristaltic pump, VK 750D digitally controlled heater/circulator, and a VK 7010 multibath $(n=8)$ dissolution testing station with automated sampling manifold.

The LC system consisted of a Shimadzu (Kyoto, Japan) LC-20AT liquid chromatograph, SPD-M10 $A_{v P}$ photodiode array detector (PDA), SIL-20A auto sampler, DGU-20A degasser, CBM-20A system controller, and Class-VP data system equipped with a reversed phase column (Nucleosil $C_{8}$ endcapped, $150 \times 4.6 \mathrm{~mm}, 100 \AA, 5 \mu \mathrm{m}$ ) from MachereyNagel (MN). The mobile phase was 70:30:0.085 acetonitrile/water/triethylamine $(\mathrm{v} / \mathrm{v} / \mathrm{v})$ at a constant flow rate of $1.5 \mathrm{~mL} / \mathrm{min}$ at room temperature $\left(23 \pm 1^{\circ} \mathrm{C}\right)$. The $\mathrm{pH}$ of the aqueous phase was adjusted to 7.5 with phosphoric acid. Aliquots of $20 \mu \mathrm{L}$ were injected. The detector was set at a wavelength of $210 \mathrm{~nm}$.

A UV-vis spectrophotometer (SHIMADZU, Japan) Model UV-1601 PC was used for spectroscopic measurements. The software employed was UVPC personal spectroscopy software, version 3.9. For all the tested solutions, the second derivative spectra $\left(D^{2}\right)$ were recorded over the range 280 $250 \mathrm{~nm}$ in a $1-\mathrm{cm}$ quartz cell, fixing $\Delta \lambda$ at $4 \mathrm{~nm}$ and scaling factor of 200.The amplitude values of $D^{2}$ were measured at $268 \mathrm{~nm}$ for MNC, zero-crossing of inactive ingredients.

An Ultrabasic potentiometer (Denver, Colorado, USA) was used for $\mathrm{pH}$ determinations, and sample filtration was carried out using Vankel filters (qualitative, $35 \mu \mathrm{m}$ ).

\section{Sink Conditions}

The solubility was determined by dissolving the highest unit dose of the drug, in this case $50 \mathrm{mg}$, in $250 \mathrm{~mL}$ of each medium tested (i.e., $0.1 \mathrm{~N} \mathrm{HCl}$ and $\mathrm{pH} 4.1$ and 7.4 USP buffers) at $37^{\circ} \mathrm{C}(2)$. Aliquots of $1 \mathrm{~mL}$ were removed after $15 \mathrm{~min}$, transferred into $10-\mathrm{mL}$ volumetric flasks, diluted with mobile phase $(20 \mu \mathrm{g} / \mathrm{mL})$, and analyzed $(n=2)$ by the LC method previously described.

\section{Dissolution Testing Conditions}

Dissolution testing was performed in compliance with USP (3) using baskets (Apparatus 1) at $50 \mathrm{rpm}$, in $900 \mathrm{~mL}$ of $0.01 \mathrm{~N} \mathrm{HCl}$ at $37 \pm 0.5^{\circ} \mathrm{C}$. Manual sampling aliquots $(5 \mathrm{~mL})$ were withdrawn at 5, 10,15,30, and $60 \mathrm{~min}$ and immediately filtered. No replacement of the medium was done. The percentage of drug dissolved was determined using both LC-UV and UV-D² methods for the same samples to compare the results, using dissolution medium as a blank.

The reference substance solution was prepared using an amount of powder equivalent to $10 \mathrm{mg}$ of MNC that was transferred to a $10-\mathrm{mL}$ volumetric flask and diluted to volume with $0.01 \mathrm{~N} \mathrm{HCl}(1.0 \mathrm{mg} / \mathrm{mL})$. A 3.0-mL aliquot of this solution was transferred to a $50-\mathrm{mL}$ volumetric flask and diluted with dissolution medium, for a final concentration of $60 \mu \mathrm{g} / \mathrm{mL}$.

\section{Dissolution Method Validation}

The proposed method was validated using both LC-UV and UV-D² methods to assay the dissolved drug. Specificity, linearity, accuracy, and precision were evaluated $(2,3)$.

\section{Stability of Standard and Sample Solutions}

The stability of MNC reference substance stock solution and capsule solutions in dissolution media was evaluated after preparation and collection $(n=3)$ at room temperature $\left(23 \pm 1^{\circ} \mathrm{C}\right)$ and after $72 \mathrm{~h}$ stored in a refrigerator $\left(8 \pm 2{ }^{\circ} \mathrm{C}\right)$.

\section{Specificity}

The usual concentration of excipients contained in the pharmaceutical formulation was based on the literature (22). An amount equivalent to one capsule was transferred to a vessel with $900 \mathrm{~mL}$ of medium at $37 \pm 0.5^{\circ} \mathrm{C}$ and stirred for $1 \mathrm{~h}$ at $50 \mathrm{rpm}$ using USP Apparatus 1 . Aliquots of this solution were filtered before LC and UV-D² analysis.

\section{Linearity}

Aliquots of MNC standard solution $(200 \mu \mathrm{g} / \mathrm{mL})$ in $0.01 \mathrm{~N} \mathrm{HCl}$ were transferred to $20-\mathrm{mL}$ volumetric flasks and diluted with dissolution medium to achieve five different concentrations: 1.0, 30.0, 60.0, 90.0, and $120.0 \mu \mathrm{g} / \mathrm{mL}$ for LC analysis and 5.0,30.0,60.0,90.0, and $120.0 \mu \mathrm{g} / \mathrm{mL}$ for UV-D2. The solutions were analyzed in triplicate every day for three consecutive days. Linearity was evaluated by linear regression analysis using analysis of variance (ANOVA). 
Table 1. Mathematical Models to Represent the Drug Dissolution Profiles

\begin{tabular}{lc}
\hline Zero-order kinetics & $Q_{\mathrm{t}}=Q_{0}+K_{0} t$ \\
\hline First-order kinetics & $\log Q_{\mathrm{t}}=\log Q_{0}+\left(K_{1} t\right) / 2.303$ \\
\hline Higuchi model & $f_{\mathrm{t}}=K_{\mathrm{H}} t^{1 / 2}$ \\
\hline Hixson-Crowell model & $W_{0}^{1 / 3}-W_{\mathrm{t}}^{1 / 3}=K_{\mathrm{s}} t$ \\
\hline
\end{tabular}

$Q_{t}$ : amount of drug dissolved in time $t$.

$Q_{0}$ : initial amount of drug in solution.

$K_{0}$ and $K_{1}$ : zero-order and first-order release constants, respectively.

$f_{:}$: amount of drug released in time $t$ by surface unity.

$K_{\mathrm{H}}$ : Higuchi dissolution constant.

$W_{0}$ : initial amount of drug in the pharmaceutical dosage form.

$W_{t}$ : amount of drug in the pharmaceutical dosage form at time $t$

$K_{s}$ : constant incorporating the surface-volume relationship.

\section{Accuracy and Precision}

Accuracy was evaluated by the recovery of known amounts of MNC reference substance added to the placebo. Aliquots of $0.45,5.4$, and $9 \mathrm{~mL}$ of the standard solution $(10 \mathrm{mg} / \mathrm{mL})$ plus an amount of excipients equivalent to one capsule were added to the vessels $(900 \mathrm{~mL})$ containing dissolution medium at $37 \pm 0.5^{\circ} \mathrm{C}$ and agitated for $60 \mathrm{~min}$ with baskets at $50 \mathrm{rpm}$. The final concentrations were $5.0,60.0$, and $100.0 \mu \mathrm{g} / \mathrm{mL}$. The analyses were done in duplicate on three different days. Repeatability (intraday) and intermediate precision (interday) were evaluated based on RSD from the recovery data.

\section{Release profiles comparison}

Student's $t$ test was used to verify whether the two methods (LC-UV and UV-D²) are equivalent for the determination of drug release. The difference factor $\left(f_{1}\right)$ and similarity factor $\left(f_{2}\right)$ were used to compare the dissolution profiles, using the LC-UV method as the reference:

$$
\begin{gathered}
f_{1}=\left\{\left[\sum_{t=1}^{n}\left|R_{t}-T_{t}\right|\right] /\left[\sum_{t=1}^{n} R_{t}\right]\right\} \times 100 \\
f_{2}=50 \cdot \log \left\{\left[1+\frac{1}{n} \sum_{t=1}^{n}\left(R_{t}-T_{t}\right)^{2}\right]^{-0.5} \times 100\right\}
\end{gathered}
$$

where $n$ is the number of time points, $R$ is the dissolution value obtained using the reference method at time $t$, and $T$ is the dissolution value obtained using the test method at the same time.

\section{Kinetic Parameters}

Four mathematical models were applied to evaluate the kinetics of drug release: zero-order, first-order, Higuchi, and Hixon-Crowell according to equations described in Table 1. Only one point greater than $80 \%$ drug released was used. The mathematical model that best expressed the dissolution profile of MNC capsules was selected based on the coefficient of determination $\left(R^{2}\right)$ or on the adjusted coefficient of determination $\left(R_{\text {adj }}{ }^{2}\right)$ values, when
Table 2. Solubility Test of Milnacipran Hydrochloride

\begin{tabular}{lccc}
\hline Medium $\left(\mathbf{3 7}{ }^{\circ} \mathbf{C}\right)$ & $\mathbf{p H}$ & $\begin{array}{c}\text { \% Drug Dissolved } \\
(\mathbf{1 5} \mathbf{~ m i n})\end{array}$ & RSD \\
\hline $0.1 \mathrm{~N} \mathrm{HCl}$ & 1.0 & 101.2 & 0.55 \\
\hline Acetate Buffer & 4.1 & 101.4 & 0.55 \\
\hline Phosphate Buffer & 7.4 & 101.9 & 0.69 \\
\hline
\end{tabular}

${ }^{a} 10 \mathrm{mg}$ of drug in $50 \mathrm{~mL}$ of medium with magnetic shaking.

${ }^{b}$ Analyzed by LC method $(n=2)$.

comparing models with different numbers of parameters. The dissolution efficiency $(\% D E)$ and sampling time for $\geq 80 \%$ of drug dissolution $\left(t_{80 \%}\right)$ were used to characterize the drug-release profile. Frequently, pharmacopoeias use this parameter as an acceptance criterion for the quantity of active ingredient dissolved expressed as a percentage of the labeled content $(Q)(3,23)$.

\section{Stability of the Pharmaceutical Dosage Form}

Drug release from capsules may change because of the reaction of the capsule shells with the contents as well as aging. Capsules prepared from gelatin are physically unstable when water content is outside the range of $12-18 \%$. Excipients and water content of dosage forms can affect the dissolution characteristics of drug product over time, and can affect its functional stability. Higher water content generally causes a larger change in dissolution behavior (24).

Changes in the dissolution rate of MNC capsules past their expiration date of 12 months after production, capsules stored at room temperature, and capsules within their expiration date after storage at $40{ }^{\circ} \mathrm{C}$ and $75 \% \mathrm{RH}$ for two and four weeks were evaluated. In the second case, samples were stored in desiccators, using saline solution $(16.7 \% \mathrm{NaCl})$ to maintain humidity.

\section{RESULTS AND DISCUSSION Dissolution Testing Conditions}

Dissolution testing should be carried out under physiological conditions, if possible, allowing interpretation of dissolution data with respect to the in vivo performance of a drug product. However, it is critical that dissolution methods developed for use as quality control (QC) tools consistently deliver reliable test results and assess drug product quality attributes (e.g., particle size, polymorphic form, or excipients). For QC purposes in general, the simplest dissolution medium is preferred whenever possible, regardless of the dosage form $(1,2)$.

The results from the solubility test (Table 2 ) show that MNC was soluble in all media tested $(0.1 \mathrm{~N} \mathrm{HCl}, \mathrm{pH} 4.1$ and 7.4 USP buffer solutions), suggesting that sink condition was achieved over the $\mathrm{pH}$ range evaluated. Since MNC presents high solubility, it could exhibit a fast dissolution rate in any medium. Therefore, the capsules were tested in $900 \mathrm{~mL}$ of $0.01 \mathrm{~N} \mathrm{HCl}(\mathrm{pH} 2.0)$, a dissolution medium that 

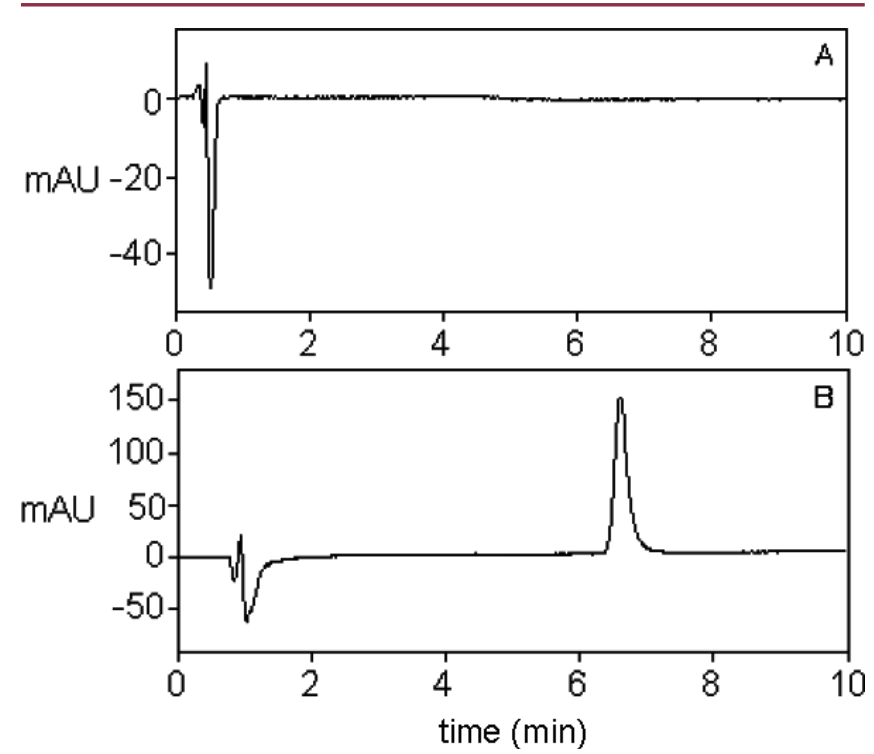

Figure 2. Specificity chromatograms of $(A)$ placebo and $(B)$ standard solution $(60 \mu \mathrm{g} / \mathrm{mL})$ of milnacipran hydrochloride in dissolution medium $(0.01 \mathrm{~N} \mathrm{HCl})$.

reflects gastric $\mathrm{pH}$, and the most likely site of dissolution for an immediate-release solid oral dosage form.

\section{Dissolution Method Validation}

$\mathrm{MNC}$ remained stable after $2 \mathrm{~h}$ at room temperature as well as for $72 \mathrm{~h}$ under refrigeration in standard and sample

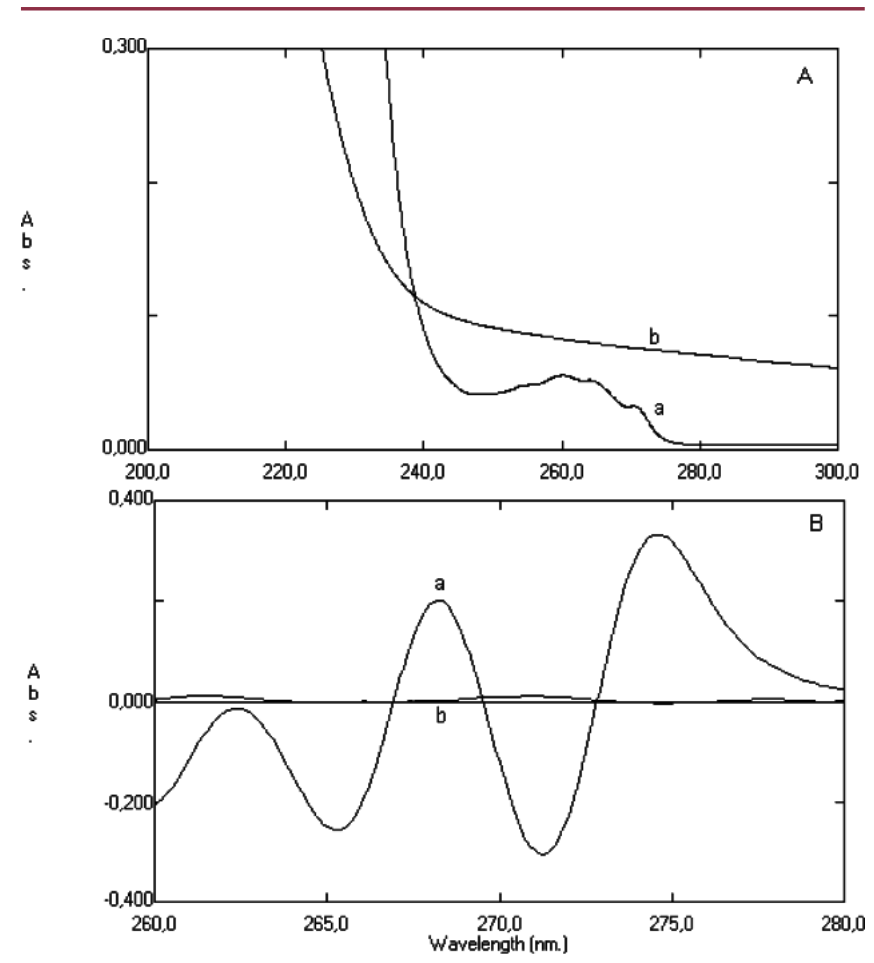

Figure 3. (A) UV-zero-order spectra and (B) UV-D2 spectra of (a) milnacipran hydrochloride standard solution $(60 \mu \mathrm{g} / \mathrm{mL})$ and (b) placebo solution in $0.01 \mathrm{~N} \mathrm{HCl}$.

Dissolution Technologies | AUGUST 2011
Table 3. Accuracy of the Dissolution of Milnacipran in Capsules

\begin{tabular}{lcc}
\hline \multirow{2}{*}{$\begin{array}{l}\text { Standard } \\
\text { solution }(\boldsymbol{\mu g} / \mathbf{m L})\end{array}$} & \multicolumn{2}{c}{ Mean Recovery \% $(\boldsymbol{n}=\mathbf{6})$} \\
\hline \cline { 2 - 3 } 5 & 97.3 & $\mathbf{U V}^{-\mathbf{D}^{2}}$ \\
\hline 60 & 98.2 & 99.5 \\
\hline 100 & 98.0 & 97.9 \\
\hline $\begin{array}{l}\text { Mean absolute } \\
\text { recovery (\%) } \pm \text { SE } \\
(n=18)\end{array}$ & $97.8 \pm 0.32$ & 97.9 \\
\hline
\end{tabular}

solutions in $0.01 \mathrm{~N} \mathrm{HCl}$ subjected to stability testing. The results ranged from $99.8 \pm 0.22 \%$ to $100.2 \pm 0.22 \%$ for solutions at room temperature, and from $100.0 \pm 0.21 \%$ to $100.4 \pm 0.21 \%$ under refrigeration (average $\pm \mathrm{RSD}$ ). No degradation was observed, and the MNC peak remained pure through PDA analysis.

The specificity of the LC-UV dissolution test method using a PDA detector demonstrated no excipient interference (Figure 2). The same analysis was done using the UV-D ${ }^{2}$ method. The results suggest that the spectroscopic method could also be used for MNC assay in dissolution testing, since the formulation excipients had no interference when using second derivative UV at $268 \mathrm{~nm}, \Delta \lambda=4$ $\mathrm{nm}$, and a scaling factor of 200 (Figure 3), considering the results of the stability test.

Linearity was suitable for both methods at the concentration ranges of $1-120 \mu \mathrm{g} / \mathrm{mL}$ (LC) and $5-120 \mu \mathrm{g} / \mathrm{mL}$ $\left(U V-D^{2}\right)$. Correlation coefficients $(r)$ were greater than 0.999 for both methods. The average equations for three calibration curves were $y=36153 x+8059$ (LC) and $y=0.0032 x-0.0016\left(U V-D^{2}\right)$. ANOVA showed significant linear regression and no significant deviation from linearity $(p<0.05)$. The measured recovery was typically $95-105 \%$ of the amount added (3). The accuracy of the methods was considered adequate in the range of $95.53-104.51 \%$ for MNC (Table 3). Repeatability and intermediate precision were evaluated at three different concentration levels $(5.0,60.0$, and $100.0 \mu \mathrm{g} / \mathrm{mL})$ over three days. The low RSD values $(\leq 5 \%)$ demonstrate the good precision of both methods. Results are presented in Table 4.

Table 4. Repeatability and Intermediate Precision of the Dissolution of Milnacipran in Capsules

\begin{tabular}{lccccc}
\hline & \multicolumn{2}{c}{$\begin{array}{c}\text { Mean observed value } \\
(\%) \pm \text { SE }\end{array}$} & & \multicolumn{2}{c}{ RSD (\%) } \\
\cline { 2 - 5 } \cline { 5 - 6 } Intraday $(\boldsymbol{n}=6)$ & LC & UV-D & & LC & UV-D \\
\hline day I & $97.2 \pm 0.48$ & $98.1 \pm 0.93$ & 1.22 & 2.33 \\
\hline day II & $97.4 \pm 0.47$ & $98.9 \pm 1.19$ & 1.19 & 2.94 \\
\hline day III & $98.9 \pm 0.48$ & $98.3 \pm 0.39$ & 1.16 & 0.98 \\
\hline Interday $(n=3)$ & $97.8 \pm 0.53$ & $98.4 \pm 0.25$ & 0.94 & 0.45 \\
\hline
\end{tabular}




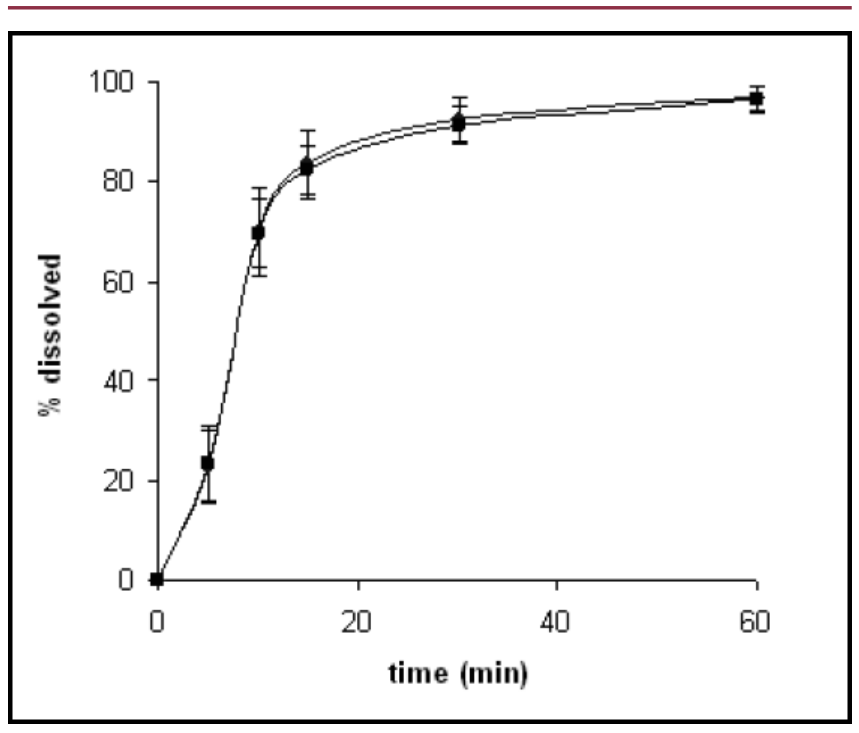

Figure 4. Dissolution profiles of 50-mg milnacipran hydrochloride capsules $(n=12)$. The values correspond to an average of 12 determinations $( \pm S D)$ by

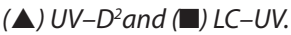

\section{Kinetic Parameters and Release Profiles Comparison}

Drug-release kinetics was evaluated through the dissolution profiles (Figure 4). According to the $R^{2}$ or $R_{\text {adj }}{ }^{2}$ valu es, dissolution profiles were best described by the HixsonCrowell model (Table 5). This model assumes that the release rate is limited by drug particle dissolution rate (23).

The sampling times for $80 \%$ of drug dissolution $\left(t_{80 \%}\right)$ using the Hixson-Crowell model were $13.3 \mathrm{~min}$ $\left(K_{S}=0.1449\right)$ by LC-UV and $12.9 \mathrm{~min}\left(K_{S}=0.1488\right)$ by

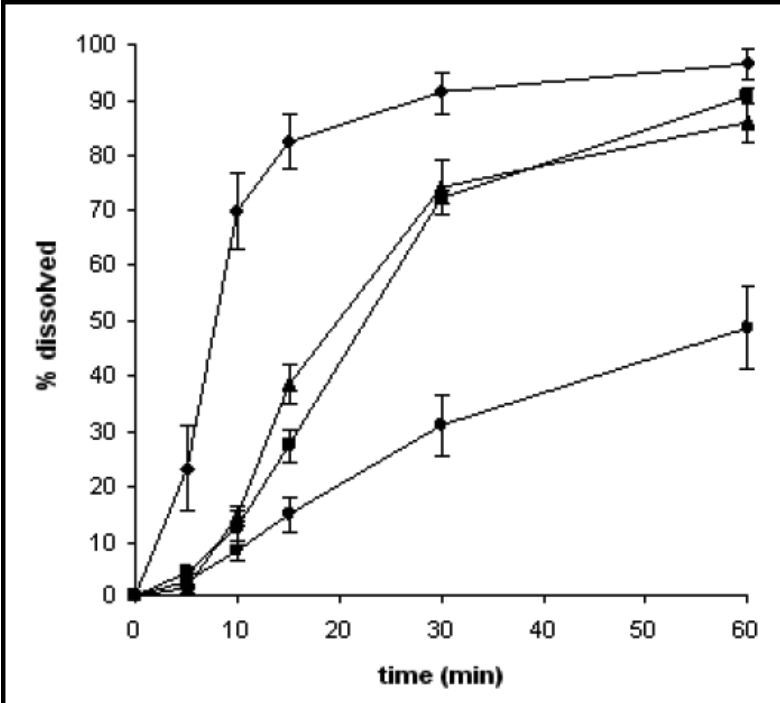

Figure 5. Dissolution profiles of milnacipran hydrochloride capsules $(\bullet)$ before storage, $(\bullet)$ after storage at room temperature and post expiration date, and after storage at $40^{\circ} \mathrm{C}$ and $75 \%$ RH for (A) 2 weeks and (口) 4 weeks.
Table 5. Coefficient of Determination $\left(R^{2}\right)$ and Adjusted Coefficient of Determination $\left(R^{2}{ }_{\text {adj }}\right)$ of the Mathematical Models

\begin{tabular}{lcccccc}
\hline \multirow{2}{*}{ Model } & \multicolumn{2}{c}{ LC-UV } & & \multicolumn{2}{c}{ UV-D } \\
\cline { 2 - 3 } \cline { 5 - 6 } & $\boldsymbol{R}^{2}$ & $\boldsymbol{R}_{\text {adj }}{ }^{2}$ & & $\boldsymbol{R}^{2}$ & $\boldsymbol{R}_{\text {adj }}{ }^{2}$ \\
\hline Zero-order kinetics & 0.9581 & 0.8953 & & 0.9590 & 0.8975 \\
\hline First-order kinetics & 0.8181 & 0.5453 & & 0.8230 & 0.5575 \\
\hline Higuchi model & 0.8947 & 0.8245 & & 0.8899 & 0.8165 \\
\hline Hixson-Crowell model & 0.9651 & 0.9128 & 0.9652 & 0.9130 \\
\hline
\end{tabular}

UV-D22. According to the acceptance limits for highly soluble and rapidly dissolving drug products, $Q=80 \%$ in $60 \mathrm{~min}$ or less is sufficient as a routine quality control test $(2,3)$. The dissolution efficiency $(\% \pm S E)$ of the pharmaceutical dosage form, defined as the area under the dissolution curve up to a certain time expressed as a percentage of the area of the rectangle described by $100 \%$ dissolution in the same time (23), was $79.8 \pm 1.06 \%$ by LC-UV and $80.5 \pm 1.25 \%$ by UV-D ${ }^{2}$.

The $t$-test was used ( $t=2.03$ for 34 degrees of freedom) to compare both methods. Nonsignificant difference was found at the $95 \%$ confidence level $(p=0.05)$, with the $t$ statistic (1.06) being less than the critical value. The drug-release profiles obtained by LC-UV and UV-D2 were compared using the difference factor $\left(f_{1}=0.67\right)$ and similarity factor $\left(f_{2}=92.52\right)$. The results indicate that the curves are similar because $f_{1}$ was less than 15 and $f_{2}$ was greater than 50 .

\section{Stability of Pharmaceutical Dosage Form}

Pharmaceutical dosage forms are complex systems composed of active pharmaceutical ingredients and various excipients that may undergo both chemical and physical degradation. It is generally accepted that the dissolution rate at room-temperature storage cannot be predicted from shorter-term storage under accelerated conditions of high temperature and humidity. On the other hand, some examples suggest that stability evaluation by accelerated tests may be possible. It is difficult to describe changes in dissolution or drug-release rates during storage by kinetic equations because of the complicated and varied mechanisms involved. However, some attempts have been made, and various empirical relationships noted (24). There was a decrease in dissolution rate for MNC capsules stored at $40^{\circ} \mathrm{C}$ and $75 \% \mathrm{RH}$ for two and four weeks, as well as for capsules after the expiration date (Figure 5), and the sampling times for $80 \%$ of drug dissolution were calculated, as shown in Table 6. As mentioned before, these changes are well known and have been previously reported. However, large changes in drug dissolution characteristics on long-term storage of the dosage form indicate that functional changes are occurring in the drug product and may compromise the in vivo performance (24). 
Table 6. Sampling Time for $80 \%$ Drug Dissolution after Stability Studies

\begin{tabular}{lcc}
\hline & \multicolumn{2}{c}{ Hixson-Crowell model (LC-UV) } \\
\cline { 2 - 3 } Storage & $\boldsymbol{t}_{\mathbf{8 0} \%}(\mathbf{m i n})$ & $\boldsymbol{K}_{\mathbf{s}}$ \\
\hline $40^{\circ} \mathrm{C}$ and 75\% RH (2 weeks) & 42.1 & 0.0458 \\
\hline $40^{\circ} \mathrm{C}$ and 75\% RH (4 weeks) & 62.6 & 0.0308 \\
\hline Room temperature (after expiration) & 119.0 & 0.0162 \\
\hline
\end{tabular}

\section{CONCLUSIONS}

A dissolution method for milnacipran hydrochloride capsules was developed and validated as a quality control test. The best condition for dissolution testing is a dissolution medium of $0.01 \mathrm{~N} \mathrm{HCl}\left(37 \pm 0.5^{\circ} \mathrm{C}\right)$ in baskets at $50 \mathrm{rpm}$. The LC-UV and UV-D² methods were used to analyze the percentage of drug dissolved versus time, and both presented acceptable specificity, linearity, precision, and accuracy. The kinetic analysis of the dissolution process is best described by the Hixson-Crowell model. The kinetic parameters $\left(K_{s}\right.$ and $\left.t_{80 \%}\right)$ estimated by the model and DE (\%) show that the formulation performed according to the proposed acceptance criteria.

Dissolution characteristics of milnacipran hydrochloride capsules subjected to different storage conditions were studied to observe changes in dissolution rate, and a slower dissolution profile was observed. Even considering the high solubility and fast absorption of MNC, the observed changes in dissolution profile were pronounced, which may affect in vivo performance, especially with capsules approaching the expiration date. However, it is important to note that the method is sensitive to these changes.

\section{ACKNOWLEDGMENTS}

This research was supported by the Medicinal Chemistry Laboratory (UFRGS). The authors would like to thank CNPQ (Brazil) for the financial support.

\section{REFERENCES}

1. Lee, S. L.; Raw, A. S.; Yu, L. Dissolution Testing. In Biopharmaceutics Applications in Drug Development; Krishna, R., Yu, L., Eds.; Springer: New York, 2008; 396.

2. Dissolution Testing of Immediate Release Solid Oral Dosage Forms; Guidance for Industry; U.S. Department of Health and Human Services, Food and Drug Administration, Center for Drug Evaluation and Research (CDER), U.S. Government Printing Office: Washington, DC, 1997.

3. The United States Pharmacopeia and National Formulary USP 32-NF 27; The United States Pharmacopeial Convention, Inc.: Rockville, MD, 2009.

4. Chen, C.; Dyck, B.; Fleck, B. A.; Foster, A. C.; Grey, J.; Jovic, F.; Mesleh, M.; Phan, K.; Tamiya, J.; Vickers, T.; Zhang, M. Studies on the SAR and pharmacophore of milnacipran derivatives as monoamine transporter inhibitors. Bioorg. Med. Chem. Lett. 2008, 18, 1346-1349.

5. United States National Library of Medicine. ChemIDplus Advanced database. http://chem.sis.nlm.nih.gov/ chemidplus/chemidheavy.jsp (accessed July 15,2011).

6. Milnacipran hydrochloride. Sigma-Aldrich Co. LLC. https://www.sigmaaldrich.com/catalog/ProductDetail. do?N4=M1318|SIGMA\&N5=SEARCH_CONCAT_ PNO|BRAND_KEY\&F=SPEC\&lang=en_US (accessed July 15,2011$)$.

7. Vaishnavi, S. N.; Nemeroff, C. B.; Plott, S. J.; Rao, S. G.; Kranzler, J.; Owens, M. J. Milnacipran: a comparative analysis of human monoamine uptake and transporter binding affinity. Biol. Psychiat. 2004, 55, 320-322.

8. Rao, S. G.; Gendreau, J. F.; Kranzler, J.D. Understanding the Fibromyalgia Syndrome. Psychopharmacol. Bull. 2008, 40 (4), 24-56.

9. Savella Prescribing Information. Forest Laboratories, Inc., 2010). http://www.frx.com/pi/Savella_pi.pdf (accessed July 15, 2011).

10. Amidon, G. L.; Lennernãs, H.; Shah, V. P.; Crison, J. R. A theoretical basis for a biopharmaceutical drug classification: the correlation of in vitro drug product dissolution and in vivo bioavailability. Pharm. Res. 1995, 12 (3), 413-420.

11. Lacassie, E.; Gaulier, J.-M.; Marquet, P.; Rabatel, J.-F.; Lachâtre, G. Methods for the determination of seven selective serotonin reuptake inhibitors and three active metabolites in human serum using highperformance liquid chromatography and gas chromatography. J. Chromatogr. B 2000, 742 (2), 229-238.

12. Tournel, G.; Houdret, N.; Hédouin, V.; Deveaux, M.; Gosset, D.; Lhermitte, M. High-performance liquid chromatographic method to screen and quantitate seven selective serotonin reuptake inhibitors in human serum. J. Chromatogr. B 2001, 761 (2), 147-158.

13. Labat, L.; Deveaux, M.; Dallet, P.; Dubost, J.P. Separation of new antidepressants and their metabolites by micellar electrokinetic capillary chromatography. J. Chromatogr. B 2002, 773 (1), 17-23.

14. Duverneuil, C.; de la Grandmaison, G. L.; de Mazancourt, P.; Alvarez, J.-C. A High-Performance Liquid Chromatography Method with Photodiode-Array UV Detection for Therapeutic Drug Monitoring of the Nontricyclic Antidepressant Drugs. Ther.Drug Monit. 2003, 25, 565-573.

15. Puozzo, C.; Filaquier, C.; Zorza, G. Determination of milnacipran, a serotonin and noradrenaline reuptake inhibitor, in human plasma using liquid chromatography with spectrofluorimetric detection. J. Chromatogr. B 2004, 806 (2), 221-228.

16. Shinozuka, T.;Terada, M.; Tanaka, E. Solid-phase extraction and analysis of 20 antidepressant drugs in human plasma by LC/MS with SSI method. Forensic Sci. Int. 2006, 162 (1-3), 108-112.

17. Uçaktürk, E.; Safak, C. Determination of Milnacipran in Human Plasma Using CG-MS. Chromatographia 2010, $72(1-2), 111-119$. 
18. Dias, C. L.; Bajerski, L.; Rossi, R. C.; Bergold, A. M.; Fröehlich, P.E. Comparative Validation Study to Assay Milnacipran Hydrochloride in Capsules by a Stability-Indicating LC and a Second Order Derivative UV Spectroscopic Methods. Pharm. Anal. Acta [Online] 2010, 1 (112). http://omicsonline.org/2153-2435/2153-2435-1-112. php (accessed Jul 14, 2011).

19. Validation of Chromatographic Methods; Reviewer Guidance; U.S. Department of Health and Human Services, Food and Drug Administration, Center for Drug Evaluation and Research (CDER), U.S. Government Printing Office:Washington, DC, 1994.

20. International Conference on Harmonization. Stability Testing of New Drug Substances and Products, Q1A(R2);
ICH Harmonized Tripartite Guideline; Geneva, Switzerland, 2003.

21. International Conference on Harmonization. Validation of Analytical Procedures: Text and Methodology, Q2(R1). ICH Harmonized Tripartite Guideline; Geneva, Switzerland, 2005.

22. Handbook of Pharmaceutical Excipients, 3rd ed.; Kibbe, A. H., Ed.; American Pharmaceutical Association: Washington, DC, 2000.

23. Costa, P.; Sousa Lobo, J.M. Modeling and comparison of dissolution profiles. Eur.J.Pharm.Sci.2001, 13 (2), 123-133.

24. Yoshioka, S.; Stella, V. J. Stability of Drugs and Dosage Forms; Kluwer Academic Publishers: New York, 2002. 